\title{
The Identification of Multi-Vehicle Moving Loads on the Single Lane Based on Influence Line Method
}

\author{
Liang HUANG ${ }^{1}{ }^{\text {a*}}$, Lei-WANG ${ }^{2}$, Shun-Yong LI ${ }^{3}$, Chu-Yu XIANG ${ }^{1}$, Heng-Qi GE ${ }^{1}$ \\ ${ }^{1}$ Chongqing Jiao tong University, Chongqing, China \\ ${ }^{2}$ CCCC Second Harbor Engineering Co. Ltd. \\ ${ }^{3}$ Qinghai local railway construction investment Co, Ltd \\ ahuangliang9368@163.com \\ ${ }^{*}$ Corresponding author
}

Keywords: Moving Load, Identification, Dynamic, Strain Influence Line, Wavelet Transform.

\begin{abstract}
The identification of moving loads based on influence line method had defects of uncounted lateral distribution of load, unapparent peak values and a low speed of recognition. To improve these disadvantages, this paper proposes a method to identify moving loads, which identified transverse positions of vehicle load according to the dynamic stress of multiple strain key points on the same cross section, peak values by Wavelet Transform method, and axle weight according to a time history cure of the dynamic strain and stress in a specific time period. Results of a simulated research on Ansys showed the accuracy of recognizing multiple vehicles on single line by the proposed approach was high.
\end{abstract}

\section{Introduction}

Moving load identification was a typical second-order inverse problem [4], which was to obtain moving loads according to a known system and responses. Using a dynamic response from an online monitoring system to identify moving loads is a way to establish a load model reflecting a normal operational state of a bridge, to improve the effectiveness of the monitoring system. Moreover, load identification was a basis for bridge design, traffic control management, and infrastructure health and safety assessment and management. Considering the reasons above, moving load identification was valuable to research.

\section{The Present Situation of Moving Load Identification}

The identification of bridge moving loads was a special and complex identification problem. Among previous research, there were two main types of methods for bridge moving loads identification: one is based on the vehicle-bridge coupling vibration model to identify interaction between vehicle and bridge [1,2,3], the other one is to distinguish the vehicle speed, axle amount, and axle weight based on dynamic responses [5,6]. Studies of moving load identification were still in the initial stage. The problem of insufficient applicability of current methods, multi-vehicle identification and sensor testing accuracy should be considered in further study.

Although the bridge moving load identification theory had some progresses, there were still some problems:

(1) The previous research was only for the one lane bridge with a span that is no more than 30 meters. Hence, the scope of the application is narrow.

(2) Previous research did not solve the problem of accurately recognizing multiple vehicles in single lane or multiple lanes. The proposed methods in previous research are to identify moving loads of a single vehicle or sparse vehicles, which is insufficient to recognize multiple vehicles.

(3) Some moving loads identification methods did not take the lateral distribution of the load into consideration, which had a negative impact on the accuracy of the methods. 


\section{Method of Identifying Moving Load Based on Influence Line}

Wang et al. studied dynamic strain responses from points in different cross sections when a vehicle crossed a bridge [5]. The vehicle's speed, axle number, and axle base were identified based on a peak value of a strain curve. Meanwhile, the vehicle's weight was determined by the proportional relationship between itself and affected area of the strain curve.

\section{Characteristics of a Bridge Stain Response Curve with Moving Vehicles}

The area of the stain curve was equal to the integration of the time axis of the stain curve during the time period from a vehicle was on bridge to the vehicle was out of bridge.

$A=\int \varepsilon(x) d x=V \int \varepsilon(t) d t$

In the equation, $\varepsilon(x)$----dynamic strain, A----area affected, V----velocity of vehicle

Previous studies found that there was a linear relationship between vehicle weight and dynamic strain curve area. Based on this perspective, vehicle weight could be directly calculated. Moreover, it was found that there was a linear relationship between the vehicle weight and any specific parts of dynamic strain curve area as well.

\section{Identification of Vehicle Speed, Axle Numbers, and Axle Base}

When a vehicle passed through the bridge, it was regarded as a group of moving concentrated force. The scale of the force was equal to the axle weight of the vehicle. The measuring point of the strain curve will appear obvious peak when the axel through the cross-section of strain measuring point. Based on this feature, some other required data can be calculated.

When the axle passed through a cross section with multiple strain key points, each strain curve of the points reached a peak. According to this, needed information of vehicle speed, axle numbers, and axle base could be obtained.

For the two strain points A, B on different cross sections of a bridge, their dynamic strain time curves were regarded as $f(t)$ and $g(t)$. The vehicle was at a constant speed. When two wheel axles of the vehicle crossed the section A, the strain time curve of the point reached two peaks A1 and A2. When two wheel axles of the vehicle crossed the section $B$, the strain time curve of the point reached two peaks $\mathrm{B} 1$ and $\mathrm{B} 2$. The distance between $\mathrm{A}$ and $\mathrm{B}$ was signed as $\Delta \mathrm{L}$, the time consumption from $\mathrm{A}$ to $\mathrm{B}$ was signed as $\Delta \mathrm{T}$, and the difference of time consumption between two wheel axles on passing through a same section was referred as $t$.

$\Delta \mathrm{L}$ was a known value that was determined by the position of measuring points; $\Delta \mathrm{T}$ was the absolute value of the subtraction of A1 from A2 (or the subtraction of B1 from B2), which was determined by a correlation function of $\mathrm{f}(\mathrm{t})$ and $\mathrm{g}(\mathrm{t})$, namely $\mathrm{C}(\tau)$.

$$
C(\tau)=\int f(t-\tau) g(t) d t
$$

In this equation, $\Delta \mathrm{T}$ is the value of $\tau$ when the value of $C(\tau)$ reached its maximum. The value of vehicle speed was $\mathrm{V}=\Delta \mathrm{L} / \Delta \mathrm{T}$.

The axle base was $\mathrm{d}=\mathrm{Vt}$. The axes number is the number of peaks on a strain curve.

\section{Identification of Axle Weight}

Based on the vehicle speed, axle number, axle base, axle weight was gained with a help of influence line techniques. The total weight of the vehicle was signed as $\mathrm{G}$, and the axle weight of the $\mathrm{i}$-th axle was signed as $\mathrm{G}_{\mathrm{axis} \_\mathrm{i}}$. These two factors met a equation as follow:

$$
G=G_{\text {axis_1 }}+G_{\text {axis_2 }}+\cdots+G_{\text {axis_n }}
$$

For the i-th axle, its corresponding vector of influence line was:

$$
L_{i}=c[0 \cdots 0 \vec{l} 0 \cdots 0]^{T}
$$


The numbers of 0 on the left and right sides of the formula were determined by the distance between the $\mathrm{i}$-th axle and the head axle, the distance between the $\mathrm{i}$-th axle and the rail axle, vehicle speed, and sampling frequency.

$$
\begin{aligned}
& L=\left[\begin{array}{llll}
L_{1} & L_{2} & \cdots & L_{n}
\end{array}\right] \\
& G_{a x i s}=\left[\begin{array}{llll}
G_{a x i s \_1} & G_{a x i s \_2} & \cdots & G_{a x i s_{-} n}
\end{array}\right]^{T}
\end{aligned}
$$

$\mathrm{LG}_{\mathrm{axis}}$ indicated the dynamic strain by fitting influence line method. $\mathrm{S}$ indicated the measured dynamic strain.

$$
\begin{aligned}
& L G_{\text {axis }}=S \\
& G_{\text {axis }}=L^{-1} S
\end{aligned}
$$

As $\mathrm{c}$ is an unknown constant, relative value of each axle weight was distinguished by formula (8). When referring formula (5), the weight of each axle was identified.

\section{The Improvement of this Paper}

In this paper, the author proposed several improvements in the influence line method as follows:

1. For single vehicle on a single lane, the relationship between the dynamic strain of different cross-sections was used to identify which lane that the vehicle was on. For multi-vehicle on a single lane, this study identified which lane that the first vehicle was on by analyzing the dynamic strain data during the period that the first vehicle was on bridge while the second one was not. Similarly, this study identified which lane that the second vehicle was on by using the dynamic strain data during the period that the first vehicle was out of bridge while the second one was not.

2. For tandem and tridem axle vehicles, due to the smaller wheelbase, the effect of each other superimposed, which may result in unapparent peaks in strain curves.

3. Gaining peak values by wavelet transform method was a new method to identify information about axle [6]. The basic idea of this method was to continuously process original dynamic strain signals with wavelet transform methods and extracted the wavelet coefficients in a specific scale. The wavelet coefficients were then processed by a local maximum method to identify peak points in strain curves.

4. For identifying axle weight in a situation that multiple vehicles were on a single lane. Take double vehicles on a single lane as an example, T1, T2, T3, T4 and influence line information can be obtained after identifying the vehicle speed V1, V2, wheelbase S1, S2 and lateral positions of each vehicle. According to the characteristics of the dynamic strain response curve, the relationships between the factors are as follows:

$$
\begin{aligned}
& \frac{G_{1}}{G_{0}}=\frac{V 1 \int_{T 1}^{T 2} \varepsilon_{s}(t) d t}{\int_{0}^{V 1 \times(T 2-T 1)} \varepsilon_{y}(x) d x} \\
& \frac{G_{2}}{G_{0}} \int_{0}^{V 1 \times(T 3-T 2)} \varepsilon_{y}(x) d x+\frac{G_{1}}{G_{0}} \int_{0}^{V 1 \times(T 3-T 1)} \varepsilon_{y}(x) d x=V 1 \int_{T 1}^{T 3} \varepsilon_{s}(t) d t \\
& \frac{G_{3}}{G_{0}} \int_{0}^{V 1 \times(T 4-T 3)} \varepsilon_{y}(x) d x+\frac{G_{2}}{G_{0}} \int_{0}^{V 1 \times(T 4-T 2)} \varepsilon_{y}(x) d x+\frac{G_{1}}{G_{0}} \int_{0}^{V 1 \times(T 4-T 1)} \varepsilon_{y}(x) d x=V 1 \int_{T 1}^{T 4} \varepsilon_{s}(t) d t \\
& \frac{G_{4}}{G_{0}} \int_{0}^{V 1 \times(T 5-T 4)} \varepsilon_{y}(x) d x+\frac{G_{3}}{G_{0}} \int_{0}^{V 1 \times(T 5-T 3)} \varepsilon_{y}(x) d x+\frac{G_{2}}{G_{0}} \int_{0}^{V 1 \times(T 5-T 2)} \varepsilon_{y}(x) d x+\frac{G_{1}}{G_{0}} \int_{0}^{V 1 \times T 5} \varepsilon_{y}(x) d x=V 1 \int_{T 1}^{T 5} \varepsilon_{s}(t) d t
\end{aligned}
$$


In this equation, ${ }^{\varepsilon_{s}}(t)$ is the value of measured dynamic strain; ${ }^{\varepsilon_{y}(x)}$ is the value of vertical axle of the influence line; G1 and G2 are the axle weights of the front axle and rail axle of the first vehicle. G3 and G4 are the axle weights of the front axle and rail axle of the second vehicle.

\section{Numerical Simulation}

For instance, two biaxial vehicles are traveling through a simple supported beam bridge. This study uses ANSYS to build bridge model, writing command flows based on Ansys Apdl to simulate the bridge dynamic strain response when the vehicles come cross the bridge.

Bridge parameters: the bridge length is $30 \mathrm{~m}$; the cross-section is composed of five T-beams; the flexural rigidity of each T-beam is $E I=10.8 \times 10^{9} \mathrm{~N} \cdot \mathrm{m}^{2}$; coefficient of damping is $\alpha=1.76076$ and $\beta=1.19871 E-003$; linear density is $\rho A=1.868 \times 10^{3} \mathrm{~kg} / \mathrm{m}^{3}$.

Layout the dynamic strain measurement points at the bottom edge of the No. 2 and No.4 beams at the $1 / 4,1 / 2,3 / 4$ of the bridge length.

Assume that all the vehicles have $3.5 \mathrm{~m}$ wheelbase. If two axle weights of a vehicle are $50 \mathrm{KN}$, the vehicle was regarded as the vehicle 1 . Similarly, if two axle weights of a vehicle are $40 \mathrm{KN}$, the vehicle was regarded as the vehicle 2 . If two axle weights of a vehicle are $30 \mathrm{KN}$, the vehicle was regarded as the vehicle 3 . The vehicle is assumed to be ahead of the vehicle 2 .

Case 1: The speed of vehicle 1 is $10 \mathrm{~m} / \mathrm{s}$ and the speed of vehicle 2 is $10 \mathrm{~m} / \mathrm{s}$. The distance of the both vehicles is $8 \mathrm{~m}$.

Case 2: The speed of vehicle 1 is $20 \mathrm{~m} / \mathrm{s}$ and the speed of vehicle 2 is $20 \mathrm{~m} / \mathrm{s}$. The distance of the both vehicles is $8 \mathrm{~m}$.

Case 3: The speed of vehicle 1 is $30 \mathrm{~m} / \mathrm{s}$ and the speed of vehicle 2 is $30 \mathrm{~m} / \mathrm{s}$. The distance of the both vehicles is $8 \mathrm{~m}$.

Case 4: The speed of vehicle 1 is $15 \mathrm{~m} / \mathrm{s}$ and the speed of vehicle 2 is $10 \mathrm{~m} / \mathrm{s}$. The distance of the both vehicles is $8 \mathrm{~m}$.

Case 5: The speed of vehicle 1 is $15 \mathrm{~m} / \mathrm{s}$ and the speed of vehicle 2 is $20 \mathrm{~m} / \mathrm{s}$. The time difference between the both vehicles entering the bridge is $0.95 \mathrm{~s}$.

Case 6: The speed of vehicle 2 is $10 \mathrm{~m} / \mathrm{s}$ and the speed of vehicle 3 is $10 \mathrm{~m} / \mathrm{s}$. The distance of the both vehicles is $8 \mathrm{~m}$.

The L/4, L/2, 3L/4 dynamic strain responses were calculated by simulating the speed as $10 \mathrm{~m} / \mathrm{s}$, $20 \mathrm{~m} / \mathrm{s}$ and $30 \mathrm{~m} / \mathrm{s}$. The dynamic strain response at the $\mathrm{L} / 4, \mathrm{~L} / 2,3 \mathrm{~L} / 4$ cross sections were calculated by simulating these six conditions(See Fig. 1-6).

Using the identification method based on dynamic strain response to Identify the number of axles, wheelbase, axle weight and gross weight of the vehicle. The results are shown in the following Tab. 1.

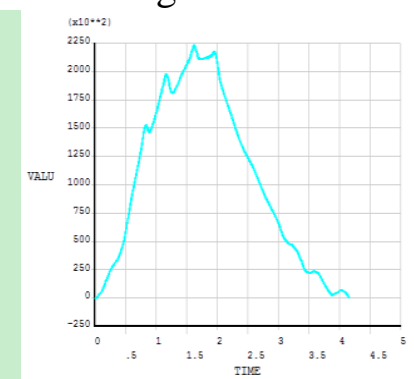

1/ 4 section of Beam 2

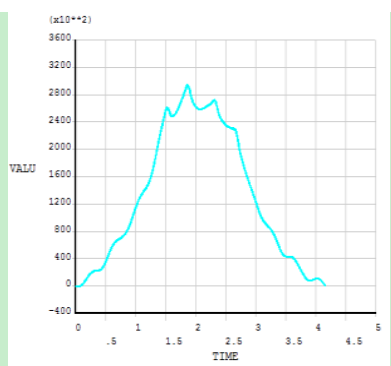

$1 / 2$ section of Beam 2

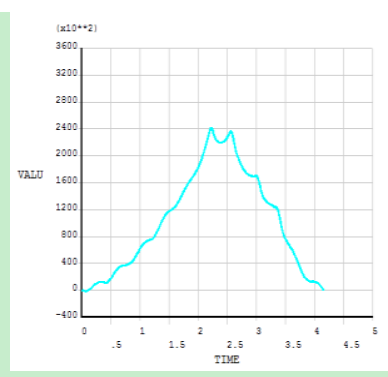

3/4 section of Beam2 1/4 section of Beam 4

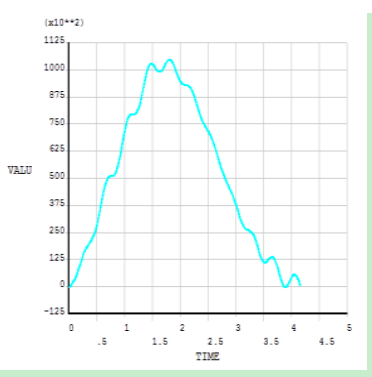

Fig. 1 The dynamic strain response based on the first condition 


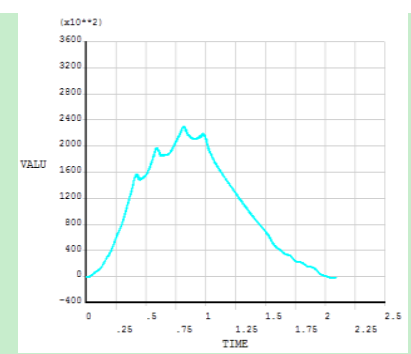

1/4 section of Beam 2

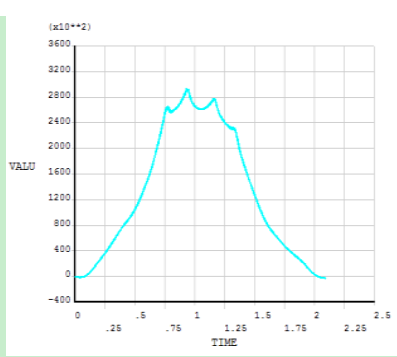

$1 / 2$ section of Beam 2

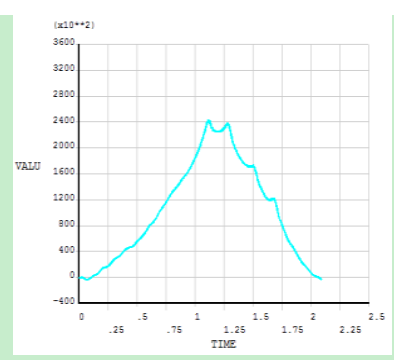

$3 / 4$ section of Beam2

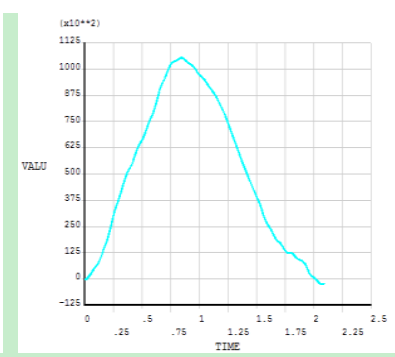

$1 / 4$ section of Beam 4

Fig. 2 The dynamic strain response based on the second condition

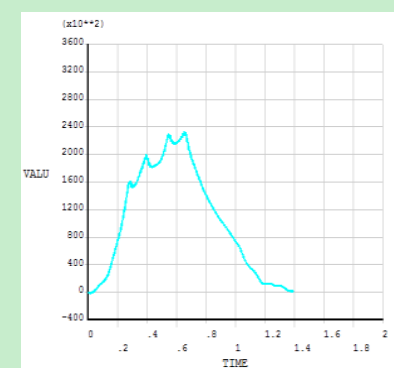

$1 / 4$ section of Beam 2

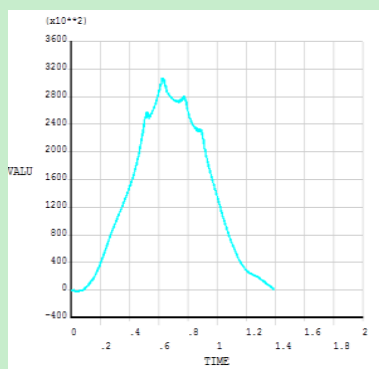

$1 / 2$ section of Beam 2

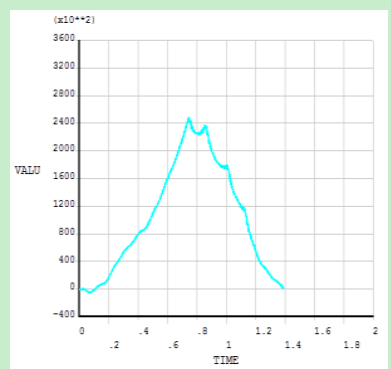

$3 / 4$ section of Beam2

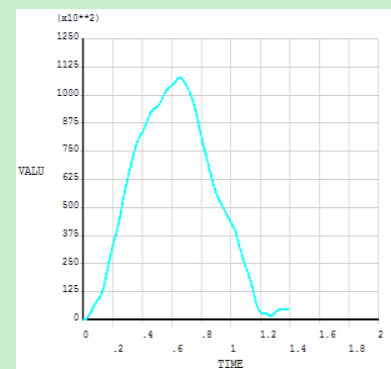

$1 / 4$ section of Beam 4

Fig. 3 The dynamic strain response based on the third condition

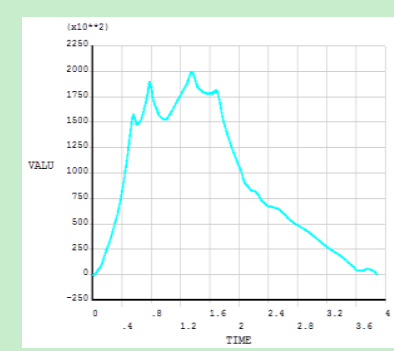

$1 / 4$ section of Beam 2

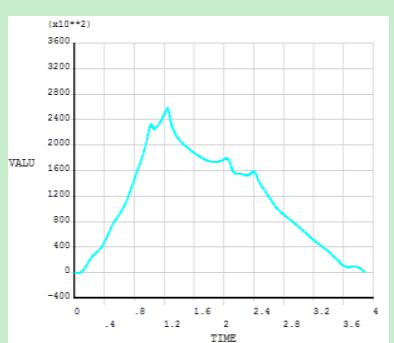

$1 / 2$ section of Beam 2

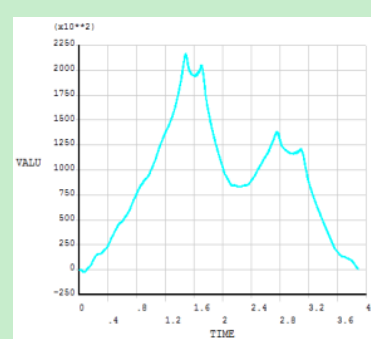

$3 / 4$ section of Beam2

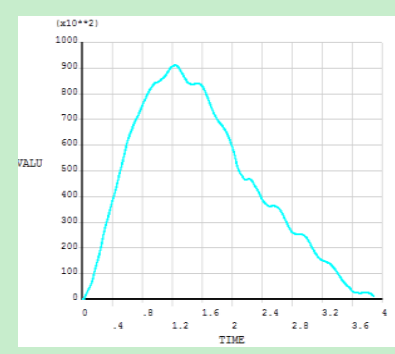

$1 / 4$ section of Beam 4

Fig. 4 The dynamic strain response based on the fourth condition

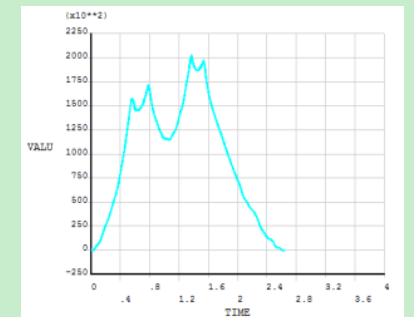

1/4 section of Beam 2

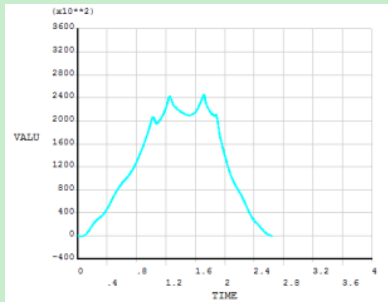

$1 / 2$ section of Beam 2

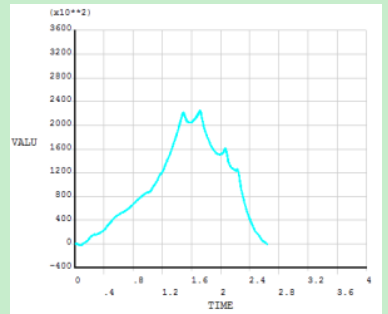

3/4 section of Beam2

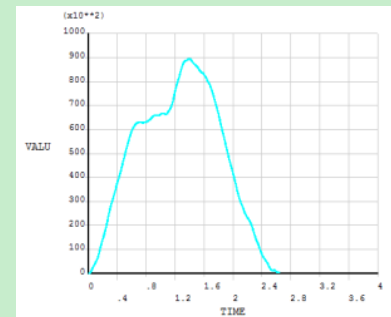

$1 / 4$ section of Beam 4

Fig. 5 The dynamic strain response based on the fifth condition

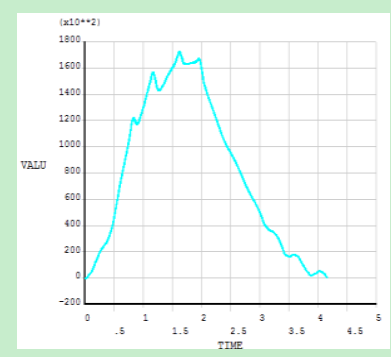

$1 / 4$ section of Beam 2

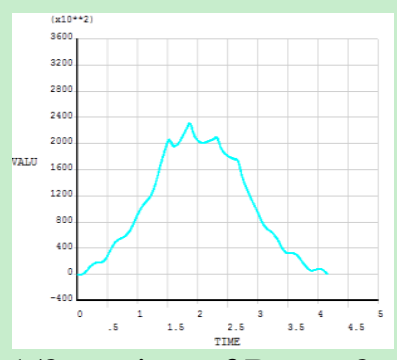

$1 / 2$ section of Beam 2

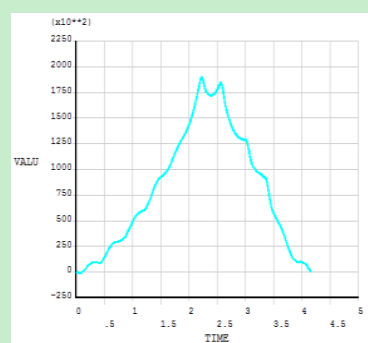

$3 / 4$ section of Beam2

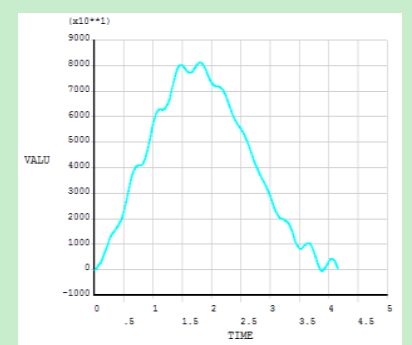

$1 / 4$ section of Beam 4

Fig. 6 the dynamic strain response based on the sixth condition 
Tab. 1 Numerical simulation results

\begin{tabular}{|c|c|c|c|c|c|c|c|c|c|c|c|c|c|}
\hline \multirow{2}{*}{\multicolumn{2}{|c|}{$\begin{array}{l}\text { Condition } \\
\text { number }\end{array}$}} & \multicolumn{3}{|c|}{ speed $(\mathrm{m} / \mathrm{s})$} & \multicolumn{3}{|c|}{ Wheelbase (m) } & \multicolumn{3}{|c|}{ Axle weight (KN) } & \multicolumn{3}{|c|}{ Lateral position } \\
\hline & & $\begin{array}{l}\text { True } \\
\text { value }\end{array}$ & $\begin{array}{l}\text { Identi } \\
\text { fying } \\
\text { value }\end{array}$ & $\begin{array}{c}\text { Error/ } \\
\%\end{array}$ & $\begin{array}{l}\text { True } \\
\text { value }\end{array}$ & $\begin{array}{l}\text { Identi } \\
\text { fying } \\
\text { value }\end{array}$ & $\begin{array}{c}\text { Error/ } \\
\%\end{array}$ & $\begin{array}{l}\text { True } \\
\text { value }\end{array}$ & $\begin{array}{l}\text { Identi } \\
\text { fying } \\
\text { value }\end{array}$ & $\begin{array}{l}\text { Erro } \\
\mathrm{r} / \%\end{array}$ & $\begin{array}{l}\text { True } \\
\text { value }\end{array}$ & $\begin{array}{l}\text { Identi } \\
\text { fying } \\
\text { value }\end{array}$ & $\begin{array}{c}\text { Error/ } \\
\%\end{array}$ \\
\hline \multirow{3}{*}{1} & vehicle 1 & 10 & 10.09 & 0.9 & 3.5 & 3.43 & 2 & 50 & 50.5 & 1 & lane 1 & lane 1 & Zero \\
\hline & & & & & & & & 50 & 52.3 & 4.6 & & & \\
\hline & vehicle 2 & 10 & 10.19 & 1.9 & 3.5 & 3.43 & 2 & $\begin{array}{l}40 \\
40\end{array}$ & $\begin{array}{l}41.2 \\
39.9\end{array}$ & $\begin{array}{c}3 \\
0.25\end{array}$ & lane 1 & lane 1 & Zero \\
\hline \multirow[b]{2}{*}{2} & vehicle 1 & 20 & 20.19 & 0.95 & 3.5 & 3.49 & 0.29 & 50 & 50.5 & 1 & lane 1 & lane 1 & Zero \\
\hline & vehicle 2 & 20 & 20.69 & 3.45 & 3.5 & 3.52 & 0.57 & $\begin{array}{l}50 \\
40 \\
40\end{array}$ & $\begin{array}{l}48.1 \\
38.5 \\
39.4\end{array}$ & $\begin{array}{c}2.6 \\
3.75 \\
1.5\end{array}$ & lane 1 & lane 1 & Zero \\
\hline \multirow{2}{*}{3} & vehicle 1 & 30 & 30.88 & 2.93 & 3.5 & 3.29 & 6 & $\begin{array}{l}50 \\
50\end{array}$ & $\begin{array}{c}46.8 \\
52\end{array}$ & $\begin{array}{l}8 \\
4\end{array}$ & lane 1 & lane 1 & Zero \\
\hline & vehicle 2 & 30 & 30.88 & 2.93 & 3.5 & 3.7 & 5.7 & $\begin{array}{l}40 \\
40\end{array}$ & $\begin{array}{l}41.2 \\
40.1\end{array}$ & $\begin{array}{c}3 \\
0.25\end{array}$ & lane 1 & lane 1 & Zero \\
\hline \multirow{2}{*}{4} & vehicle 1 & 15 & 15 & 0 & 3.5 & 3.4 & 2.86 & $\begin{array}{l}50 \\
50\end{array}$ & $\begin{array}{l}50 \\
46\end{array}$ & $\begin{array}{l}0 \\
8\end{array}$ & lane 1 & lane 1 & Zero \\
\hline & vehicle 2 & 10 & $\begin{array}{c}10.09 \\
6\end{array}$ & 0.96 & 3.5 & 3.47 & 0.85 & $\begin{array}{l}40 \\
40\end{array}$ & $\begin{array}{l}39.6 \\
38.9\end{array}$ & $\begin{array}{c}1 \\
2.75\end{array}$ & lane 1 & lane 1 & Zero \\
\hline \multirow{2}{*}{5} & vehicle 1 & 15 & 15 & 0 & 3.5 & 3.4 & 2.86 & $\begin{array}{l}50 \\
50\end{array}$ & $\begin{array}{l}50 \\
46\end{array}$ & $\begin{array}{l}0 \\
8\end{array}$ & lane 1 & lane 1 & Zero \\
\hline & vehicle 2 & 20 & 20.19 & 0.95 & 3.5 & 3.49 & 0.28 & $\begin{array}{l}40 \\
40\end{array}$ & $\begin{array}{c}39.2 \\
40\end{array}$ & $\begin{array}{l}2 \\
0\end{array}$ & lane 1 & lane 1 & Zero \\
\hline \multirow{2}{*}{6} & vehicle 1 & 10 & 10.09 & 0.9 & 3.5 & 3.49 & 0.28 & $\begin{array}{l}40 \\
40\end{array}$ & $\begin{array}{l}39.5 \\
42.3\end{array}$ & $\begin{array}{l}1.25 \\
5.75\end{array}$ & lane 1 & lane 1 & Zero \\
\hline & vehicle 2 & 10 & 10.29 & 2.9 & 3.5 & 3.43 & 2 & $\begin{array}{l}30 \\
30 \\
\end{array}$ & $\begin{array}{l}30.5 \\
29.1\end{array}$ & $\begin{array}{c}1.7 \\
3 \\
\end{array}$ & lane 1 & lane 1 & Zero \\
\hline
\end{tabular}

\section{Conclusions}

This paper was mainly to use the influence line theory to identify moving load of multiple vehicles in a single lane by researching dynamic strain responses. Based on the a numerical simulation of coupled vibration of vehicles and bridge, the conclusions are as follows:

(1) The proposed method in the study for identifing the bridge moving load reuqires a small num ber of system parameters. Besides, feasibility and identification accuracy of the method are great, w hich is advantagous when compared with the traditional method.

(2) The key point of the method is the accurate identification of vehicle speed, which requires tha $\mathrm{t}$ dynamic strain responses are sampled frequently enough. This is to ensure adequate data points wh en the vehicle is on the bridge.

(3) This moving load identification method is fit for bridge with a smoothly deck and heavy axle. Meanwhile, the speed of vehicles is in a general status. Further study will be a research on the light and high-speed vehicle that is on a bridge with rough surface.

(4) The location of the strain measuring point will affect the accuracy of the moving load identification. Other factors that may affect the identification of the moving load on the bridge still need to be studied.

\section{Acknowledge}

This work was supported by Science and Technology Innovation Talents of Chongqing (CSTCKJCXLJRC17 ), cstc2015jcyjBX0014,cstc2016jcyja0022. 


\section{References}

[1] O'Conner C, Chan T.H.T. Dynamic wheel load from bridge strain [J]. Journal of Structural Engineering ASCE, 1988, 114(8):1703 1723.

[2] Xiangrong Yuan, Enli Chen, Shaopu Yang. Identification of Moving Loads from Beam Response [J], Vibration Test and Diagnosis, 1995, 15 (3): 30-34.

[3] Chan T.H.T, Law S, Yung T H, et al. An interpretive method for moving force identification[J]. Journal of Sound and Vibration, 1999, 219 (3):503-542.

[4] Zhongxian Li, Feng Chen. Identification and Parameter Analysis of Moving Loads on Simply Supported and Multi-span Continuous Beam[J]. Engineering Mechanics, 2006, 23 (12): 91-99.

[5] Ningbo Wang, Weixin REN, Miao Li. Identification of bridge moving loads based on influence lines[J]. Journal of Vibration and Shock, 2013, 32(2):129-133.

[6] Ningbo Wang, Weixin REN, Wen-yu He. Wavelet Transform Wavelet Transform Method for Moving Vehicle Axles on Bridge [J] .Techniques and Engineering for Vibration Engineering, 2013, 26 (4): 539-543. 